\title{
A Formação Inicial na Concepção Docente: Um Estudo Fenomenológico com Professores de Ciências Biológicas
}

\section{The Initial Education in the Teaching Conception: A Phenomenological Study with Biological Science Teachers}

\author{
Ravi Cajú Duré \\ Brasil \\ Francisco José Pegado Abílio \\ Brasil
}

O presente estudo teve como objetivo analisar o curso de licenciatura em Ciências Biológicas da Universidade Federal da Paraíba, a partir das concepções de professores de Biologia que se formaram no respectivo curso. A metodologia foi desenvolvida a partir da abordagem qualitativa, com base no método fenomenológico-descritivo, no qual aplicamos entrevistas para a coleta e análise dos dados. A seleção e fechamento amostral foi desenvolvida de acordo com a amostragem por cotas, com a investigação dos relatos de dez professores a respeito do fenômeno da formação inicial. Como resultado identificamos 122 assertivas significativas relacionadas ao fenômeno investigado, sendo 63 vinculadas aos êxitos e 59 às críticas ao referido curso. Em relação aos êxitos identificamos a emergência de três temas que representaram as essências fenomenológicas gerais: 1) Os Projetos Extracurriculares são fundamentais para formação docente; 2) As aulas práticas do curso servem como modelo para as aulas no ensino médio; 3) O curso forma bem no que se refere aos saberes disciplinares da Biologia. Em relação às críticas identificamos três temas: 1) As aulas da Licenciatura são voltadas para a formação de um Bacharel; 2) Nos componentes pedagógicos aprende-se educação geral e pouco Ensino de Biologia; 3) Algumas teorias didático-pedagógicas da formação são pouco viáveis na escola. A emergência dessas temáticas demonstra aspectos centrais para que a formação inicial consiga realizar reestruturações curriculares condizentes com as reais demandas formativas dos professores de Biologia.

Palavras-Chave: Formação Inicial de Professores de Biologia; Concepções Docentes; Necessidades Formativas.

This study aimed to evaluate the Biological Sciences program of the Federal University of Paraiba through the conceptions of Biology teachers who graduated in the respective course. The methodology was developed from a qualitative approach, based on a phenomenological-descriptive method, in which we applied interviews to perform the data collection and analysis. Sample selection and size were determined according to a quota sampling method, by investigating the reports of ten teachers about the initial education phenomenon. As a result, we identified 122 significant associations 
related to the investigated phenomenon, of which 63 were related to the successes and 59 to the criticisms to the mentioned course. Regarding the successes, we identified the emergence of three subjects that represented the general phenomenological essences: 1) The Extracurricular Projects are fundamental in the initial education; 2) The practical classes of the course represent a model for the high school classes; 3 ) The course accomplishes the formation on disciplinary knowledges of Biology. Concerning the criticism, we identified three subjects: 1) The undergraduated classes aimed at the formation of a Bachelor; 2) The pedagogical component contains just general education and little about the teaching of Biology; 3) Some didactic-pedagogical theories present in the undergraduate classes are not feasible at school. The emergence of these subjects demonstrates central aspects that pave the way for a curricular restructuring consistent with the real formative demands of Biology teachers.

Keywords: Initial Education of Biology Teachers; Teaching Conceptions; Formative Needs.

\section{Introdução}

Os professores desempenham um papel estratégico no desenvolvimento das sociedades. De acordo com Tardif (2014), grande parte do avanço quantitativo e qualitativo dos saberes e das tecnologias de que presenciamos seria inconcebível sem um desenvolvimento correspondente dos sistemas de ensino, dos processos educativos e dos professores, nas mais variadas áreas do saber-fazer humano.

Para além desses avanços tecnológicos e científicos, Pimenta (2012) atribui ao docente um papel central na mediação dos processos constitutivos da cidadania dos sujeitos, contribuindo para a superação do fracasso e das desigualdades no âmbito escolar e, consequentemente, social.

Apesar dessa centralidade do professor diante de uma perspectiva de avanços sociais, tecnológicos e humanos, Leite (2004, p.12) chama a atenção para a enorme contradição que o docente vive, uma vez que, "mal preparado, direcionado para uma carreira de baixo status social, o educador que aí está não dá conta de uma tarefa cuja importância, complexidade e responsabilidade pressupõe um profissional altamente capacitado". Grande parte dessa contradição e dessas dificuldades nasce na formação inicial, nos desafios enfrentados por todo o sistema de formação de professores e na pouca importância destinada às licenciaturas no contexto brasileiro do ensino superior.

Diante desse quadro preocupante, é necessário reforçar que os fatores políticos, estruturais e profissionais são determinantes para que reais mudanças sejam implementadas no campo da formação. Afinal de contas, sem estrutura adequada, bons salário e planos de carreira, nenhuma classe pode avançar em qualidade e atratividade profissional. Todavia, também é notório que os avanços nas políticas e condições de trabalho docente só proporcionarão as transformações desejadas se estiverem atrelados a melhorias curriculares e didáticas nos cursos de formação profissional. 


\section{A formação de professores no contexto das Ciências Biológicas: identidade, desafios e perspectivas}

Pensar sobre a formação docente nos leva, imediatamente, a perceber os desafios de formar profissionais críticos, tecnicamente capacitados e conscientes das amplas funções sociais da escola; em um contexto cultural de desvalorização da educação e de seus profissionais (em termos reais e não apenas no campo dos discursos vazios). Essa cultura de desvalorização atua, também, dentro das próprias instituições de ensino superior, haja vista que muitas vezes os próprios professores formadores priorizam a pesquisa e a produção tecnológica em detrimento do ensino e da formação docente. Essa problemática é acentuada no contexto dos cursos de Ciências Biológicas, nos quais a identidade do bacharelado se sobrepõe à identidade da licenciatura, criando um espaço formativo pouco estimulante para o desenvolvimento da pesquisa educacional e dos saberes docentes em sua totalidade (Ayres, 2005; Diniz-Pereira, 2000).

Tal conjuntura de desvalorização da formação de professores de Ciências e Biologia apresenta uma forte relação com a construção histórica de seu currículo formal ${ }^{1}$, o qual, desde sua criação em 1939 (através do decreto 1.190/1939) tem priorizado os conteúdos específicos $^{2}$ da área da Biologia em detrimento dos conteúdos didático-pedagógicos (modelo curricular conhecido como “ $3+1$ ”).

Apesar das atuais diretrizes para as licenciaturas brasileiras indicarem a necessidade de desarticulação entre os cursos de bacharelado e licenciatura para a criação de currículos com identidade profissional própria (DCN, 2001), nas Licenciaturas em Ciências Biológicas ainda predomina um curso que privilegia a formação técnica nas áreas de Meio Ambiente, Biotecnologia e Saúde, predominando o ensino desses conhecimentos específicos no lugar da formação do licenciando para os vários contextos de realidade da educação básica (Ayres, 2005; Diniz-Pereira, 2013).

Nessa perspectiva, Carvalho e Gil-Pérez (2011) apontam que as licenciaturas precisam superar esses desafios formativos através de um curso que rompa com visões simplificadoras e reducionistas sobre o ensino de Ciências, levando o licenciando a: conhecer os conteúdos das disciplinas; questionar as ideias docentes de "sensocomum" sobre o ensino e a aprendizagem (os saberes da experiência pré-profissional e os preconceitos com a profissão); saber analisar criticamente o ensino tradicional, aprofundando o entendimento sobre suas limitações; saber preparar atividades capazes de gerar uma aprendizagem efetiva; saber dirigir o trabalho dos alunos; saber avaliar; e por fim adquirir a formação necessária para associar ensino e pesquisa didática. Tais necessidades precisam estar atreladas às concepções de formação dos professores formadores, visto que na universidade ainda predomina o entendimento do ensino como

1 Durante o trabalho utilizamos os conceitos de currículo formal como "aquele que é estabelecido pelos sistemas de ensino ou instituição educacional"; e de currículo real como o "currículo que, de fato, acontece na sala de aula em decorrência de um projeto pedagógico e dos planos de ensino" (Libâneo, 2001, p.99).

2 No decorrer do trabalho utilizamos as expressões "conteúdos específicos" e/ou "áreas específicas" para nos referir às áreas de Biotecnologia, Meio Ambiente e Saúde (de acordo com o parecer CFBio nº 01/2010). 
uma atividade centrada na exposição do professor sobre determinadas informações, confundindo aprendizagem com a memorização de conteúdos e a replicação de técnicas e procedimentos.

Diante desses desafios, consideramos que a formação de professores de Ciências e Biologia possui um longo caminho até o alcance de uma estrutura ideal de curso para a formação de um professor crítico-reflexivo (tanto a nível de currículo formal, quanto real). Todavia, é crucial que a pesquisa se aprofunde na compreensão das especificidades de cada curso, bem como nas demandas particulares dos profissionais de cada área, para que seja possível apontar estratégias que consigam empreender uma melhor formação de professores para atuar na educação básica e superior.

\section{As contribuições do estudo sobre as concepções docentes para as Licenciaturas em Ciências Biológicas}

Os trabalhos sobre as concepções docentes inserem-se no amplo campo da investigação sobre o pensamento do professor. De acordo com Matos e Jardilino (2016), o conceito de concepção remete a um sistema de explicações sobre um determinado fenômeno, que abarca conceitos, representações e preconceitos de cada sujeito, atingindo tanto a crítica quanto a valorização das experiências vivenciadas.

Essas concepções se formam a partir das reflexões que os professores desenvolvem no decorrer de seu percurso formativo e profissional. Através de suas experiências na formação inicial e continuada, e das novas descobertas desenvolvidas durante seu trabalho pedagógico e sua história de vida, os docentes formulam suas concepções sobre educação, ensino, aprendizagem, formação, legitimando ou ressignificando o que aprenderam no decorrer de sua trajetória formativo-profissional. Tais conhecimentos se desenvolvem com base no que uma série de autores do campo da formação docente conceituam como saberes docentes.

Segundo Tardif (2014), a formação de um professor é construída através de quatro dimensões do saber: os saberes profissionais, compostos pelos conhecimentos didáticopedagógicos da profissão; os saberes disciplinares, que tratam dos conhecimentos da área específica do docente (Biologia, Matemática, Geografia, entre outros); os saberes curriculares, que dizem respeito ao campo dos conhecimentos sobre o currículo (o que se deve ensinar); e os saberes da experiência, os conhecimentos originados a partir do trabalho docente cotidiano, e das reflexões sobre educação produzidas durante a vida do docente ainda enquanto aluno da educação básica e dos cursos de formação inicial e continuada.

Dentre essas quatro categorias Pimenta (2012) e Tardif (2014) indicam que os saberes da experiência constituem o eixo central do saber docente, pois é a partir dele que se relacionam os demais saberes (profissionais, disciplinares e curriculares), com os saberes desenvolvidos pelo próprio professor no cotidiano de seu trabalho. Acaba assim por influenciar diretamente na condução de sua prática profissional e na construção e reconfiguração de suas concepções sobre os vários aspectos que compõem o campo da 
educação.

Segundo Feitosa e Leite (2011) e Pimenta (2012), esses saberes da experiência são formados a partir das reflexões elaboradas no ambiente profissional do professor e nas suas experiências de vida, incorporando os conhecimentos obtidos através da observação dos seus professores (ainda enquanto alunos da educação básica ou superior), das representações que a sociedade elabora a respeito da profissão docente e das reflexões elaboradas no decorrer de sua prática profissional.

Nesse sentido, quando optamos por investigar as concepções sobre formação com professores atuantes, temos como intuito incorporar suas reflexões construídas a partir de todos os saberes docentes de base, somado aos saberes da experiência profissional. Dessa forma investigamos as concepções sobre formação elaboradas por professores que apresentam um conhecimento mais aprofundado sobre o cotidiano escolar e sobre as demandas dos professores do ensino básico (fugindo às limitações do pensamento docente espontâneo). Tal como ressalta Sousa, Moura e Sá-Carneiro (2013, p.56)

A valorização da experiência docente é um ponto de grande importância para uma nova visão na formação de professores de Ciências, pois na formação docente para o ensino de Ciências, não se encontra espaço para uma troca de experiências didáticas entre a universidade e a escola. A universidade forma para o exercício docente sem saber ao certo o que a escola precisa, quais seus anseios, que dúvidas têm os professores de ciências.

Diante dessas questões, entendemos que a compreensão dos professores de Biologia sobre a formação inicial corresponde a uma rica fonte de conhecimento que deve ser levada em consideração para a reformulação dos currículos das licenciaturas. Assim, desenvolvemos essa pesquisa com o objetivo de analisar as concepções de professores de Biologia a respeito dos êxitos e críticas a seu curso de formação inicial no que tange a aproximação entre a Licenciatura em Ciências Biológicas e os contextos de realidade da educação básica.

\section{Pressupostos metodológicos da pesquisa}

Para o desenvolvimento desta pesquisa foi utilizada a abordagem qualitativa com base no paradigma epistemológico da Fenomenologia. A análise e a coleta dos dados se basearam no método fenomenológico-descritivo, e a definição da amostra se deu através da amostragem por cotas.

A abordagem qualitativa se baseia na compreensão dos fenômenos a partir da perspectiva dos sujeitos que os vivenciam e do ambiente social no qual estão inseridos. É desse ambiente que o pesquisador qualitativo recolhe os dados em função de uma compreensão mais direta dos indivíduos, programas ou qualquer outro objeto de estudo; levando-o a compreender os contextos cotidianos da vida, caracterizando e descrevendo com profundidade o fenômeno estudado (Creswell, 2014).

No contexto das pesquisas qualitativas, o presente trabalho se fundamentou no paradigma epistemológico da Fenomenologia; compreendida como uma linha 
de pensamento filosófico que se expandiu para as pesquisas empíricas e passou a ser utilizada como paradigma teórico-metodológico de investigação dos significados que as pessoas atribuem aos fenômenos que vivenciam (Moreira, 2004; Creswell, 2014).

De acordo com Moreira (2004), a investigação fenomenológica se foca em fenômenos particulares, nos quais o pesquisador utiliza da percepção intuitiva para ler os relatos de experiência dos sujeitos de forma aprofundada. Nesse caminho, o pesquisador analisa e identifica as estruturas dos fenômenos estudados e desenvolve uma descrição das experiências, indicando a unicidade do fenômeno descrito (sua essência fenomenológica).

No contexto do escopo teórico-metodológico apresentado, a presente pesquisa adotou o método fenomenológico-descritivo de acordo com Colaizzi (1978) e Moreira (2004), investigando o fenômeno da formação docente a partir das concepções de professores de Biologia, desenvolvidas durante sua experiência na formação inicial do curso de Licenciatura em Ciências Biológicas da Universidade Federal da Paraíba (Campus I).

\section{Amostragem, coleta e análise dos dados}

Para o delineamento amostral adotamos a amostragem por cotas, que de acordo com Creswell (2014) e Sampieri, Collado e Lúcio (2013) é uma técnica que define a amostra a partir de três etapas de seleção: estudo do universo amostral em função das características relevantes para as questões do estudo; classificação da população desse universo em cotas com características semelhantes; e organização da coleta de dados em cada uma das cotas previamente estabelecidas.

Para a delimitação do universo amostral optamos pela seleção de professores de Biologia com a mesma formação inicial, partindo do princípio que investigamos a concepção docente sobre a formação. Assim, iniciamos o processo de seleção de cotas com os professores de Biologia formados na Universidade Federal da Paraíba (Campus I).

Desde a criação do referido curso, apenas três projetos curriculares foram implantados (sendo o terceiro implementado muito recentemente, no final de 2018). Assim, classificamos o universo amostral em duas cotas com características semelhantes: professores formados no primeiro projeto curricular do curso de Licenciatura em Ciências Biológicas da UFPB (que vigorou entre 1987 e 2008); e professores formados no projeto curricular que vigorou de 2008 até 2018.

Além dessas duas cotas, adotamos como critérios de inclusão: 1) ministrar Biologia no ensino médio; 2) ministrar aulas em João Pessoa (mesma cidade da licenciatura em análise); 3) possuir mais de um ano de experiência como docente.

O tempo de um ou mais anos de experiência como professor de Biologia do ensino médio se justifica pela intenção de detectar a influência dos saberes da experiência profissional na construção das concepções sobre a formação inicial, no contexto de experiência com o ensino médio. A escolha por professores atuantes nas escolas de João 
Pessoa se deu pelas diferenças dos contextos de experiência que o trabalho em escolas de outras cidades poderia gerar, tendo em vista que também se trata da mesma cidade onde ocorreu a formação inicial dos professores entrevistados.

Para realizar a seleção dos participantes da pesquisa buscamos o contato com todos os licenciados formados no projeto curricular de 2008. Iniciamos a busca ativa com essa cota por ser a mais recente, e todos os egressos possuíam contatos registrados no banco de dados da coordenação do curso. Todos os licenciados foram contatados para averiguar se preenchiam aos critérios de inclusão da pesquisa e só então foram convidados a participar do estudo. Com o número máximo de participantes selecionados dentro da primeira cota, buscamos uma quantidade igual de professores da segunda cota.

$\mathrm{Na}$ seleção da primeira cota (professores egressos do projeto curricular 2008), identificamos 67 licenciados. Destes 67, não conseguimos entrar em contato com 18 (por terem trocado de e-mail e número de telefone). Dos 49 licenciados com os quais conseguimos contato, 31 afirmaram nunca terem ministrado aulas para a educação básica, e um licenciado não possuía mais de um ano de experiência como professor. Dos 17 restantes, 12 afirmaram não ensinar em João Pessoa, resultando em um total de cinco (05) professores de Biologia para a primeira unidade de coleta.

Replicamos o mesmo número de professores para o projeto curricular antigo, estabelecendo um total de dez professores participantes do estudo, sendo cinco deles formados no currículo 2008 (cota 1) e cinco formados no currículo 1987 (cota 2). Para a coleta dos dados foram utilizadas entrevistas semiestruturadas com a finalidade de captar as descrições das experiências com o fenômeno da formação inicial.

Todas as entrevistas foram gravadas e transcritas integralmente ${ }^{3}$, com uma duração média de 50 minutos e sendo iniciadas pelas seguintes perguntas orientadoras: "Quais suas considerações gerais sobre a Formação Inicial?"; "Quais disciplinas da sua formação inicial mais contribuem com sua prática pedagógica?"; "Quais temáticas de estudo, projetos ou conhecimentos da sua formação inicial mais contribuem com sua prática pedagógica atual?". Desenvolvemos novas perguntas a partir do que os professores entrevistados iam relatando para que a influência do entrevistador nas respostas fosse reduzida ao máximo.

A adoção dessas três questões norteadoras teve como intuito estimular a reflexão do entrevistado sobre suas memórias da formação (que em alguns casos datavam de mais de 10 anos); captando tanto concepções positivas quanto negativas. Além disso, como uma de nossas intenções foi explorar a visão de professores atuantes, entendemos ser fundamental incluir questões que tinham como orientação a relação entre a formação inicial e a realidade cotidiana da escola, por isso optamos por duas questões que se direcionassem a esse ponto (abrindo espaço para uma visão sobre a estrutura curricular e extracurricular da licenciatura em estudo).

3 Para a gravação das entrevistas utilizamos um gravador de voz, e a transcrição das entrevistas foi realizada com auxílio do programa Express Scribe Transcription Software. 
A análise dos dados das entrevistas foi realizada através de análise fenomenológicadescritiva, que se baseia no movimento analítico de compreensão, interpretação e nova compreensão dos relatos (Colaizzi, 1978). Durante esse movimento, o pesquisador não deve levar em consideração as hipóteses e teorias que possam influenciar sua interpretação dos dados, a fim de que influencie o mínimo possível na leitura das experiências relatadas.

Adotamos esse método de análise por entendermos que a experiência vivenciada pelos professores de Biologia (em seus respectivos cursos de licenciatura), constitui um fenômeno consideravelmente subjetivo, o que exige do pesquisador a utilização de estratégias que se debrucem sobre a identificação dos reais significados atribuídos pelos sujeitos à experiência vivenciada com o fenômeno.

A análise fenomenológica-descritiva de Colaizzi (1978) é realizada através de sete etapas, sendo elas: 1) Transcrição e leitura de todas as respostas dos participantes, de forma a adquirir uma visão geral dos relatos; 2 ) Retorno a cada relato para a extração de frases que tratam, diretamente, do fenômeno investigado (momento de extração das "assertivas significativas"); 3) Atribuição dos sentidos a cada assertiva significativa, etapa chamada de "formulação de sentidos"; 4) Repetição da formulação de sentido em todas as entrevistas, organizando-as em um conjunto de temas (em seguida esses temas são analisados em comparação com os relatos originais, de forma a validá-los); 5) Integração dos temas em uma descrição exaustiva do tópico investigado; 6) Formulação da descrição do fenômeno investigado em uma declaração de sua estrutura; 7) Retorno a cada participante perguntando sobre a adequação dos resultados obtidos.

Após realizar essas etapas de análise, o pesquisador deve integrar os conjuntos de temas e elaborar uma descrição aprofundada das experiências, sua estrutura essencial fenomenológica (Colaizzi, 1978; Creswell, 2014; Moreira, 2004). Adotamos como critério de estabelecimento da essência fenomenológica as temáticas que emergiram nas entrevistas de $50 \%$ ou mais dos sujeitos entrevistados.

Em relação aos procedimentos éticos da pesquisa, seguimos todas as orientações contidas na Resolução do Conselho Nacional de Saúde (CNS; 510/2016). Os professores de Biologia que participaram da pesquisa assinaram o termo de compromisso livre e esclarecido (TCLE), e o projeto foi aceito pelo Comitê de Ética em Pesquisas da UFPB (CEP/UFPB).

Os nomes dos professores entrevistados foram devidamente resguardados, substituindo-os pelos termos "prof. 01, prof. 02", e assim sucessivamente. Para resguardar a imagem dos professores formadores, quando citados, substituímos pelos termos "professor x". 


\section{Resultados e Discussão}

A título de organização dos resultados e discussões apresentamos os dados dos professores egressos dos dois currículos investigados de forma compilada. Nas questões peculiares aos professores egressos de um determinado currículo inserimos um novo tópico para discutir o tema de forma específica.

Durante as entrevistas foram identificadas 122 assertivas significativas relacionadas com o fenômeno investigado, sendo 63 vinculadas aos êxitos da Licenciatura em Ciências Biológicas, e 59 vinculadas às críticas da formação.

\section{Perfil dos professores entrevistados}

Participaram da pesquisa dez professores de Biologia, sendo oito mulheres e dois homens, apresentando uma média de idade de 35 anos. A experiência profissional dos participantes da pesquisa variou entre dois e doze anos, com uma média de 6 anos. Em relação à carga-horária de ensino enfrentada pelos docentes, o número de horas trabalhadas oscilou entre 15 e 47 horas semanais (somando o tempo dos professores que trabalham dando aulas regulares de reforço), resultando em uma média de 29 horas de trabalho semanal.

Em relação aos dois currículos de licenciatura nos quais os participantes cursaram a formação inicial, cinco deles estudaram no currículo de 1987 (professores 1, 2, 3, 6 e 9) e os outros cinco no currículo de 2008 (professores 4, 5, 7, 8 e 10). Sobre suas formações complementares, cinco docentes não eram formados em nenhum tipo de pós-graduação e os outros cinco tinham cursado mestrado, doutorado e especializações, sendo três delas em áreas relacionadas à Educação, e dois casos relacionadas (exclusivamente), à área de Biodiversidade e Meio Ambiente.

Tais dados nos conferem o entendimento de um perfil majoritariamente feminino, com profissionais relativamente jovens e com uma alta carga-horária de trabalho docente. A formação dos professores variou entre metade apenas com graduação, e a outra metade com formação acadêmica aprofundada e majoritariamente vinculada ao campo da Educação, ocorrendo casos de desarticulação entre a identidade profissional do biólogo docente e a identidade profissional do biólogo técnico-pesquisador das áreas específicas.

\section{Os êxitos da Licenciatura em Ciências Biológicas na concepção docente}

Os professores entrevistados consideraram exitosos os projetos extracurriculares vinculados ao universo pedagógico, bem como o aprendizado dos conteúdos específicos (saberes disciplinares). Relataram, também, que as atividades práticas que participaram durante as disciplinas acabaram servindo como modelo que eles adaptam e replicam atualmente como professores de ensino médio (Tabela 01). 
Tabela 01. Categorização fenomenológica em relação aos êxitos da formação inicial dos professores de Biologia expressas nas entrevistas.

\begin{tabular}{lcc}
\hline Temas & Assertivas & Professores \\
\hline $\begin{array}{l}\text { - Os Projetos Extracurriculares são fundamentais para formação } \\
\text { docente. }\end{array}$ & 20 & $90 \%$ \\
\hline $\begin{array}{l}\text { - As aulas práticas do curso servem como modelo para as aulas no ensino } \\
\text { médio. }\end{array}$ & 14 & $70 \%$ \\
\hline $\begin{array}{l}\text { - O curso forma bem no que se refere aos saberes disciplinares da } \\
\text { Biologia. }\end{array}$ & 8 & $50 \%$ \\
\hline $\begin{array}{l}\text { - PIBID como espaço fundamental de prática e observação da prática } \\
\text { docente durante a formação. }\end{array}$ & 18 & $50 \%$ \\
\hline - As avaliações das disciplinas do curso auxiliam na aprendizagem. & 2 & $10 \%$ \\
\hline - Formação exitosa para educação inclusiva. & 1 & $10 \%$ \\
\hline Fonte: Dados da pesquisa (2018)
\end{tabular}

A relevância de projetos extracurriculares, aulas práticas-demonstrativas e os conteúdos específicos foram os aspectos centrais dos relatos. Avaliações bem preparadas e o ensino de como realizar uma educação inclusiva emergiram apenas na entrevista de um professor, não se caracterizando, portanto, como essência fenomenológica do tema.

\section{Os Projetos Extracurriculares são fundamentais para formação docente}

A temática mais recorrente no que se refere aos êxitos do curso foi a importância da participação em projetos extracurriculares relacionados com as áreas da Educação (Tabela 01). Para os professores que entrevistamos, a participação nesses projetos foi um momento fundamental de identificação profissional, reflexões sobre as realidades da escola e sobre a aplicação das práticas e teorias pedagógicas com as quais tiveram contato durante as disciplinas do curso.

Dentre os três projetos extracurriculares citados como exitosos na formação (PIBID, PROLICEN e Monitoria), o PIBID foi o projeto mais valorizado, tendo sido citado por $50 \%$ dos professores. Como se trata de um projeto relativamente recente (criado através da portaria $\mathrm{n}^{\circ} 38$ de 2007 do MEC), só emergiu como assertiva significativa nos relatos de professores formados no currículo de 2008. Ou seja, todos os professores que vivenciaram o PIBID o apontaram como um programa fundamental para sua formação.

(...) se não existisse o PIBID eu não estaria preparado. Uma vez que na formação os professores não nos preparam para uma licenciatura. (Prof. 04)

(...) eu peguei experiência pra chegar em uma escola boa e dizer "Tenho experiência. De quê?? De sala de aula estadual, do PIBID, quer que eu de uma aula pra você?". Então eu me sentia confiante porque eu já tinha dado aula. (Prof. 04)

Nas falas do professor 04 fica perceptível que o PIBID foi o programa que o fez vivenciar o universo escolar, possibilitando-o desenvolver os saberes da experiência docente, o que gerou mais confiança em relação a suas habilidades e conhecimentos. 
Resultado similar foi identificado nos trabalhos de Feitosa e Gomes (2016) e Sousa et al. (2016), os quais demonstraram que, nos relatos dos licenciandos participantes do PIBID, o projeto contribuiu para a aquisição de experiência real com o trabalho docente, obtidos através da vivência direta na escola de ensino básico, experiência fundamental na reflexão sobre a prática docente e experimentação de variadas metodologias didáticopedagógicas.

Os professores 07 e 10 também ressaltaram o papel do PIBID como primeiro momento em que o licenciando vivencia o espaço escolar como professor, deparandose com os desafios de trabalhar na escola. Tal experiência foi marcante no sentido de despertar e consolidar a identificação profissional com o trabalho docente.

(...) é uma experiência que quando você chega na sala de aula, você se depara com o PIBID é a hora que você "eu quero ou não? Eu não quero e vou embora para o Bacharel, ou pra outro curso". (Prof. 07)

(...) como eu participei desde praticamente quando eu entrei na universidade, do PIBID, então desde o terceiro período até eu terminar o curso eu estava em escola, praticamente toda semana. Então eu via um pouco de como era a rotina, apesar de não ser a professora da turma, mas eu estava na rotina da escola. (Prof. 10)

No momento em que os bolsistas observam e vivenciam situações reais do trabalho docente sentem-se mais seguros para, futuramente, exercer essa profissão. Para Feitosa e Leite (2011) e Tardif (2014), essa aprendizagem é similar ao aprendizado produzido no exercício da atividade profissional, contexto no qual esses saberes são construídos a partir de situações reais, singulares e específicas do ambiente escolar, fazendo com que o PIBID empreenda um papel fundamental para o fortalecimento da identidade docente e dos saberes da experiência individual e coletiva, um tipo de saber-fazer e de saber-ser professor.

Outro projeto extracurricular citado pelos professores de nossa pesquisa foi o Programa de Apoio às Licenciaturas (PROLICEN). Nas entrevistas foi possível identificar que o programa vem exercendo seu papel de aproximar os licenciandos da pesquisa nas áreas da Educação e Ensino, emergindo como programa que propicia uma reflexão crítica a partir da literatura científica do campo da Educação e de observações advindas das experiências durante a realização das pesquisas na escola. Para o professor 02, a experiência com o programa o levou a reflexões que repercutem em sua concepção de educação e prática pedagógica atual.

(...) eu trago reflexões desse projeto até hoje pra minha concepção de educação, pra minha prática em sala de aula. [Projeto vinculado ao PROLICEN]. [Entrevistador: Você pode aprofundar um pouco mais sobre o que esse projeto te trouxe de importante?] Prof. 02: Muito relacionado a compreender o ecossistema que tá ao redor da comunidade escolar. Ou seja, nesse projeto, nós trabalhávamos a educação ambiental na região do bioma Caatinga. Era muito impactante ver que todos os livros de Biologia das escolas que se situavam nesse Bioma não falavam quase nada sobre Caatinga. E como os estudantes não se identificavam com o debate ecológico que tava posto no livro. (Prof. 02) 
Esses projetos de pesquisa também são uma oportunidade para que o licenciando em Ciências Biológicas conheça, com mais profundidade, o universo teórico dos pesquisadores das várias áreas da Educação. Segundo o professor 06, foi durante o PROLICEN que ele realmente aprofundou suas leituras didático-pedagógicas.

(...) o que eu aprendi eu devo ao estágio, às leituras que eu fiz durante o "estágio", às pessoas com que eu convivi, que me ensinaram bastante. Convivia com [professor $\mathbf{x}, \mathbf{y} \mathbf{e}$ z], com todo aquele pessoal que respira educação ali, 24 horas. E eu não vi essas literaturas no currículo da Biologia, eu vi durante o PROLICEN. (Prof. 06) [o estágio que o relato apresenta se refere ao estágio como bolsista PROLICEN]

Para Lüdke (2009), além do papel formativo da pesquisa, há que se ressaltar que a área de ensino ainda carece de estudos que ajudem no aperfeiçoamento das teorias didático-pedagógicas. Apesar de não ser esse o objetivo primário do PROLICEN, ao trabalhar com a pesquisa pedagógica durante a formação inicial, o programa acaba, também, incentivando a formação de pesquisadores educacionais, influenciando o fortalecimento de uma maior identificação com o contexto das pesquisas da área didático-pedagógica e, consequentemente, a identidade docente nas experiências da formação inicial.

Nos cursos de Licenciatura em Ciências Biológicas, o PIBID, o PROLICEN e a Monitoria ganham um valor ainda maior por atuarem como programas de estímulo à formação de educadores desde o início da graduação. Nos currículos em análise, os estágios supervisionados que levam o graduando a vivenciar a realidade de uma sala de aula só entram no último ano do percurso formativo, condição que retarda o desenvolvimento de vínculos identitários com a escola e com o campo da Educação.

Destacamos também que, nos cursos de Ciências Biológicas, esses programas cumprem um importante papel formativo por disputarem com os laboratórios de pesquisa das áreas específicas, desde o início do curso, o vínculo extracurricular dos graduandos. Em nosso entendimento, esses vínculos são determinantes na influência do projeto identitário pessoal e, consequentemente, das trajetórias formativas e profissionais dos licenciandos, influenciando na evasão ou manutenção do estudante na área de Educação.

\section{As aulas práticas do curso servem como modelo para as aulas no ensino médio}

A importância atribuída às aulas práticas durante o curso apareceu em $70 \%$ das entrevistas, demonstrando como essas atividades foram marcantes na formação dos professores de Biologia entrevistados.

(...) as disciplinas que me trouxeram mais a prática do que a teoria mesmo. Então, as disciplinas de Metodologia e Instrumentação para Biologia; Educação, Saúde e Meio Ambiente; e Pesquisa, foram as disciplinas que trouxeram bastante coisas que a gente aproveita mesmo em sala de aula. Atividades práticas que a gente consegue utilizar com os nossos alunos, metodologias que a gente consegue aplicar com eles. Então, hoje em dia eu 
uso muitas coisas que foram feitas com a gente em sala de aula, uso com os meus alunos, e isso são coisas bem relevantes pra mim. (Prof. 07)

(...) era algum tipo de estágio, 1 ou 2, não sei. Que a gente tinha que fazer uma oficina e apresentar pra uma banca com [professor x e y]. Foi uma disciplina que foi marcante pra mim porque foi quando eu vi, não só comigo mas também com meus colegas, a busca por maneiras alternativas de trabalhar certos conteúdos. (Prof. 03)

As aulas práticas, tanto das disciplinas específicas quanto das didáticopedagógicas, foram compreendidas como momentos de observação e aprendizagem ativa que levavam o licenciando a refletir e testar teorias da educação e técnicas de ensino, unindo os conhecimentos teóricos e práticos aprendidos durante o curso. Foram citadas como estratégias eficazes para a formação de professores as oficinas, microaulas, aulas demonstrativas e simulações práticas de análises ambientais.

(...) [Professor $\mathbf{x}$ ] foi um professor que fez muita diferença, então ele tem uns modelos bem legais para explicar circulação e respiração que eu uso até hoje. Eu construí o meu e guardei, e disse "professor vou ficar pra mim". Então eu consegui fazer e até hoje eu tenho. Eu preciso até refazer o modelo que tá velho. Então a disciplina dele foi perfeita para a licenciatura. (Prof. 10)

Segundo Krasilchik (2004), as aulas práticas são uma modalidade didática fundamental para levar o aluno a compreender melhor os conteúdos propostos, levando-o a experimentar e aprender as habilidades e os assuntos trabalhados. A realização de experimentos, práticas e demonstrações que levam o licenciando a interagir diretamente com o conteúdo representam uma excelente ferramenta para que se possa compreender a relação indissociável entre teoria e prática (da educação básica ao ensino superior).

Todavia, nos relatos foi possível perceber que as práticas das disciplinas específicas não eram ministradas com o objetivo de ensinar a desenvolver aulas práticas na escola, e sim com o objetivo exclusivo de ensinar o conteúdo específico em si. O que os professores entrevistados relataram foi que aprenderam por observação e replicação, através do que Feitosa e Leite (2011) reconhecem como saberes da experiência pré-profissional (saberes docentes elaborados enquanto o futuro professor era aluno). Nessa dinâmica, o licenciando precisa desenvolver a adaptação pedagógica de forma improvisada, sem o direcionamento pedagógico de um profissional da formação de professores de Ciências e Biologia.

No relato do professor 04 podemos observá-lo exaltando a atividade prática de morfologia vegetal, atividade ministrada todos os semestres do curso para alunos da licenciatura e do bacharelado, mas que o professor entrevistado (no contexto do ensino médio), precisa modificar e adaptar essa aula prática para aplicá-la na escola básica.

(...) por causa daquelas aulas lá de [professora $\mathbf{x}$ ] eu faço até hoje, eu saio na rua catando as folhas, as flores e dou minha aula simples, não preciso parar não, marcar e perder tempo: "galera faz aí umas ilhas de 5 alunos"... e eu vou e pego a florzinha e gineceu, androceu. Graças a essa atitude de [professora x]. (Prof. 04) 
Desenvolver uma aula prática com o objetivo de trabalhar o conteúdo é diferente de ministrar uma aula prática com o objetivo de ensinar o conteúdo específico e as habilidades para o desenvolvimento dessas aulas no futuro espaço de atuação profissional do licenciando em formação. Por mais que as aulas práticas tenham sido citadas como um ponto exitoso do currículo real do curso em análise, o ideal seria que essas aulas não fossem só voltadas para a explicação dos saberes disciplinares, mas também para o desenvolvimento dos saberes profissionais e curriculares.

\section{0 curso forma bem no que se refere aos saberes disciplinares da Biologia}

Durante os relatos também foi possível identificar o êxito do curso em ensinar os conteúdos biológicos específicos (saberes disciplinares), indicando a eficiência em relação aos conhecimentos de Botânica, Zoologia, Biologia Molecular e demais áreas específicas das Ciências Biológicas.

(...) e não tem como não mencionar as próprias disciplinas que me deram a base de... na verdade é isso, a minha formação me ajudou com a base de conteúdo. (Prof. 03)

(...) a formação contemplou bem o conteúdo. Alguns conteúdos a gente realmente não utiliza, mas auxilia de maneira indireta em outros ou nas curiosidades dos alunos. (Prof. 10)

O currículo tinha coisas muito boas com relação às disciplinas básicas da Biologia. Zoologia, Fisiologia Animal. (Prof. 09)

Foi possível observar nas entrevistas que existe uma concepção consistente de que, nos conteúdos específicos da Biologia, o curso preparou bem para a docência, sendo esses saberes disciplinares constituintes de uma dimensão fundamental para a prática docente (Pimenta, 2012; Tardif, 2014).

(...) é, primeiro tem que ter conhecimento específico da sua disciplina, porque, na minha concepção um professor não é só um facilitador entre o conteúdo, o livro e o aluno não. $O$ professor domina um conteúdo e há uma distinção entre o professor e o aluno. O professor tem o conhecimento específico, o aluno pode ter uma vivência específica, pode ter outros conhecimentos, pode ter conhecimentos empíricos, mas são conhecimentos distintos. Eles precisam dialogar, isso não é uma hierarquia de conhecimento, mas é uma distinção. Então primeiro ele tem que ter um conhecimento específico. (Prof. 02)

O mesmo resultado foi identificado no estudo de Pandolpho (2006), que ao aplicar questionários para 33 professores de Biologia da rede pública de Campinas (SP), identificou que, na concepção deles, o curso de licenciatura formou bem no que se refere aos conteúdos específicos exigidos para ensinar Biologia no ensino médio. No estudo de Souza e Fonseca (2014), os professores também relataram se sentir bem preparados no que tange aos conteúdos específicos da área de Biologia.

Se por um lado esse dado representa um êxito do curso em análise, por outro é resultado da existência de um currículo preponderantemente voltado aos saberes 
disciplinares. Nos currículos do curso analisado na presente pesquisa, mais da metade de seus componentes se voltam ao ensino das disciplinas específicas (83\% das disciplinas obrigatórias do curso no currículo antigo e 65\% no currículo de 2008). Ressaltamos que esse aspecto problemático também foilembrado por $30 \%$ dos professores entrevistados em nossa pesquisa, emergindo como crítica ao currículo de sua formação inicial (Tabela 2).

De acordo com Ayres (2005) e Diniz-Pereira (2010), essa matriz curricular, somada à influência da tradição bacharelesca presente nos cursos de Ciências Naturais, contribui para uma formação desequilibrada e limitada no que se refere à abrangência de dimensões do saber-fazer docente. Tal condição atribui às Licenciaturas em Ciências Biológicas o desafio de buscar o equilíbrio entre componentes curriculares voltados para os vários tipos de saberes docentes sem prejudicar a formação em nenhuma dimensão de sua profissionalidade.

\section{As críticas à Licenciatura em Ciências Biológicas na concepção docente}

Os temas que emergiram como essências fenomenológicas na dimensão das críticas ao curso caracterizaram o distanciamento entre a Licenciatura em Ciências Biológicas e o contexto da educação básica. Na visão dos professores entrevistados, o currículo, as ementas dos componentes e a prática de ensino dos professores formadores não pareciam ter como objetivo central a formação de um professor (Tabela 02).

Tabela 02. Categorização fenomenológica das críticas à formação inicial dos professores de Biologia expressas na entrevista

\begin{tabular}{lcc}
\hline Temas & Assertivas & Professores \\
\hline - As aulas da licenciatura são voltadas para a formação de um Bacharel. & 10 & $60 \%$ \\
\hline $\begin{array}{l}\text { - Nos componentes pedagógicos aprende-se educação geral e pouco } \\
\text { Ensino de Biologia. }\end{array}$ & 5 & $50 \%$ \\
\hline $\begin{array}{l}\text { - Algumas teorias didático-pedagógicas da formação são pouco viáveis } \\
\text { na escola. }\end{array}$ & 5 & $50 \%$ \\
\hline - O currículo de 1987 apresenta poucas disciplinas pedagógicas. & 9 & $30 \%$ \\
\hline - Ausência de conteúdos presentes no currículo escolar. & 7 & $30 \%$ \\
\hline - Formação excessivamente centrada nos conteúdos específicos. & 10 & $30 \%$ \\
\hline - O licenciado precisa ser autodidata para se tornar professor. & 2 & $10 \%$ \\
\hline - O Projeto Curricular não é construído de forma interdisciplinar. & 2 & $10 \%$ \\
\hline - Ausência de avaliação do trabalho dos professores formadores. & 1 & $10 \%$ \\
\hline
\end{tabular}
Fonte: Dados da pesquisa (2018).

As temáticas que apresentaram maior ocorrência nos relatos dos entrevistados mostraram um curso de licenciatura desarticulado da realidade escolar nas dimensões do currículo formal e real, tanto nas disciplinas específicas quanto nas didático-pedagógicas. A seguir, apresentaremos as críticas que emergiram como essências fenomenológicas gerais das entrevistas com os professores. 


\section{As aulas da Licenciatura são voltadas para a formação de um Bacharel em Biologia}

Os sujeitos pesquisados relataram que em muitas disciplinas específicas o professor formador não ministrava aulas voltadas para a formação de um licenciando, que futuramente se tornaria professor de Ciências e Biologia (ou pesquisador educacional), mas para um futuro bacharel, técnico e pesquisador nas áreas específicas da Biologia.

Essa crítica emergiu nas entrevistas de $60 \%$ dos professores investigados, tanto dos egressos do currículo de 1987 quanto dos de 2008 (Tabela 02).

(...) prepara apenas para o conhecimento da Biologia. Pra que eu saiba a definição do que é um órgão, pra que eu saiba encaixar um animal numa classe, num domínio, num reino. Prepara para ser uma Bióloga, não uma professora de Biologia... Eu acho assim, ainda é muito enraizado no bacharelado. (Prof. 06)

Meu currículo não era um currículo que preparava pra sala de aula. Apesar de ter a licenciatura, a gente era muito formado para ser bacharel, para a área de pesquisa, para qualquer outra coisa menos pra sala de aula. (Prof. 01)

(...) por conta do curso da gente ser misturado do Bacharelado para a licenciatura, os professores não associavam o conhecimento técnico à prática educacional. Então eles achavam que todos os alunos eram de bacharel, que não tinha ninguém que ia ser professor. (Prof. 09)

As aulas dos conteúdos específicos não formavam o licenciado com o objetivo de ensiná-lo a ensinar aqueles conteúdos, nem a associar o saber disciplinar e curricular daqueles assuntos com o contexto da escola básica. Esse objetivo didático faz toda a diferença, pois o planejamento e desenvolvimento de uma aula necessitam do domínio integrado entre os saberes docentes, passando pela compreensão do conteúdo, conhecimento de técnicas eficientes para ensiná-lo e sua relação curricular com o saber escolar. Essa desarticulação entre o saber disciplinar e os demais saberes docentes também ficou evidente no tema que aponta a ausência de conteúdos do currículo escolar durante a licenciatura (Tabela 02).

(...) eu entendo que a universidade não preparou em alguns assuntos, como a questão da histologia que no meu currículo foi retirado e eu tenho que dar aula disso. Tá entendendo o problema? (Prof. 08)

Mesmo com o avanço expresso na mudança curricular de 2008, que separou a entrada no curso entre licenciados e bacharéis e aumentou a proporção de componentes didático-pedagógicos, as concepções docentes sobre esse problema se mantiveram ${ }^{4}$. No currículo de 2008, em mais da metade do curso (65\% dos componentes curriculares), o aluno da licenciatura cursava disciplinas específicas (muitas vezes compartilhadas com

4 A exigência pela desarticulação entre o currículo formal dos cursos de Bacharelado e Licenciatura foi implementada através do parecer CNE/CP 009/2001, referente à homologação das Diretrizes Curriculares Nacionais para a Formação de Professores da Educação Básica. 
os alunos bacharéis), que visavam o desenvolvimento de habilidades e competências destinadas à formação profissional dos alunos do bacharelado, como relata o professor 07:

(...) eles deviam formular a ementa da disciplina, os métodos de avaliação, o plano do curso, de um modo geral, voltado para a formação de um professor. Porque se eu tô numa graduação para me formar professor eu preciso ter base para isso. Por mais que o conteúdo tenha que ser passado (o mesmo conteúdo), mas a maneira é diferente. A maneira como um Bacharel vai utilizar a Biologia da Conservação, por exemplo, é totalmente diferente da maneira que um licenciado vai utilizar a Biologia da Conservação na sala de aula. Então eu acho que a formação deveria ser baseada em como eu vou utilizar isso na minha vida profissional. (Prof. 07)

Com base nesses relatos é possível compreender que os professores entrevistados defendem a adoção de estratégias curriculares que integrem o ensino de determinado conteúdo específico a momentos de desenvolvimento didático-pedagógico desses conteúdos. Para eles, em um curso de licenciatura não basta ensinar as características dos grupos taxonômicos de seres vivos, é fundamental que também sejam trabalhadas formas de ensinar esses conteúdos para o contexto da educação básica em sua dimensão didática e curricular.

Quando os professores relatam que as disciplinas eram ministradas com o objetivo de formar um bacharel, evidenciam uma formação inicial que valoriza o percurso formativo e profissional atrelado às áreas de Meio Ambiente, Saúde e Biotecnologia, influenciando negativamente na formação do licenciando e na dinâmica de fortalecimento de sua identificação profissional. Aos que mesmo influenciados por tal concepção formativa se mantinham no caminho da docência, sua formação havia se constituído de forma deficitária nas dimensões didático-pedagógicas dos componentes curriculares específicos.

Esse modelo de licenciatura que tem seu currículo formal e real voltado à formação de bacharéis é um relato presente, também, nos estudos sobre as licenciaturas em Física de Camargo, Nardi e Rubo (2014) e Garcia e Pozo (2017), demonstrando que se trata de um fenômeno mais amplo, presente nas licenciaturas em ciências naturais como um todo.

A influência das concepções sobre formação docente, de professores do bacharelado, no currículo real e formal das licenciaturas, é um fenômeno que vem pautando as discussões curriculares há bastante tempo (Ayres, 2005; Cacete, 2014). Diz respeito às dificuldades de desenvolvimento da identidade de um curso que ao ser criado a partir de outro tem seu currículo fundido a essa estrutura de valores, tradições, culturas e concepções de ciência, formação, ensino e aprendizagem. Quando diferentes concepções sobre a formação entram em conflito (no contexto de cursos superiores compartilhados por professores de bacharelado e licenciatura), a tendência comum é o favorecimento das visões compartilhadas pela maioria dos professores. Como o bacharelado é uma modalidade mais tradicional, na qual atua uma maior quantidade de docentes em uma maioria de componentes curriculares, esses conflitos tendem a 
resultar na adoção das concepções dos professores bacharéis; mesmo quando falamos do currículo formal e real de cursos de formação de professores.

Identificar que os professores da escola básica (mesmo depois de formados), continuam a apresentar críticas diretas à forma como professores bacharéis desenvolvem suas aulas na formação dos licenciados, nos mostra que os cursos de formação de professores de Ciências e Biologia precisam construir uma identidade formativacurricular própria, com a clara finalidade de formar um professor e/ou pesquisador educacional.

\section{Nos componentes pedagógicos aprende-se educação geral e pouco ensino de Biologia}

Em relação às disciplinas pedagógicas do curso, os professores participantes da pesquisa relataram que elas tratavam das temáticas gerais de educação, sendo pouco relacionadas ao ensino de Biologia de forma específica. Essa crítica emergiu nas entrevistas de 50\% dos professores investigados, tanto dos egressos do currículo de 1987 quanto do de 2008.

(...) eu acho que o currículo tem uma questão marcante, tecnicista, pouco articulada com ensino de Biologia. É tanto que eu li pouquíssimo, pouquíssimo! Na verdade, só li em uma ou duas disciplinas sobre Ensino de Biologia. (Prof. 02)

(...) os professores da educação não relacionavam nada com Biologia, porque boa parte deles não eram biólogos. Só temos 4 professores que eram realmente biólogos que conseguiam mostrar algumas coisas que eram realmente da Biologia, mas os outros professores não, porque eram de departamentos diferentes. (Prof. 10)

De acordo com os relatos, seria importante que existissem mais disciplinas relacionadas com o Ensino de Biologia, ou os professores formadores (e a ementa das disciplinas), construíssem uma maior contextualização entre os conhecimentos didáticopedagógicos e o contexto do ensino, relacionando os campos da Psicologia, Sociologia, História e Filosofia da Educação com a Didática das Ciências. Tais ajustes ajudariam tanto no entendimento dos conteúdos quanto da sua relação com os futuros contextos profissionais dos licenciandos em formação.

As disciplinas da licenciatura eram licenciatura de uma maneira geral, mas o Ensino de Biologia, de Ciências, no currículo que vivenciei, é muito falho. (Prof. 03)

Ao analisarmos o currículo de 1987, observamos que das 36 disciplinas obrigatórias apenas seis eram vinculadas à área de Educação (16\%) e, apenas em Prática de Ensino em Biologia ( $8^{\circ}$ semestre do curso), a temática específica do Ensino de Ciências e Biologia era apresentada na ementa.

Esses números reforçam a crítica relatada pelos professores entrevistados, demonstrando que no currículo de 1987 o profissional que era formado para se tornar professor de Ciências e Biologia acessava apenas uma disciplina sobre o ensino dessas temáticas, no último semestre do curso. Tal estrutura curricular representava as 
concepções de formação de professores que deram origem às licenciaturas brasileiras na década de 1930, através do modelo “ $3+1$ ” de formação. Esse modelo formativo anacrônico priorizava os saberes disciplinares em detrimento dos demais saberes docentes, desenvolvendo um curso de formação de professores descontextualizado das habilidades e competências que fazem parte das atribuições profissionais de um professor (sobretudo da educação básica) (Diniz-Pereira, 2010).

Ao desenvolver a mesma análise com o currículo de 2008, pudemos identificar um aumento significativo na quantidade de disciplinas do campo da Educação e do Ensino. Das 52 disciplinas obrigatórias 16 eram vinculadas à área de Educação (31\%) e em nove delas foi possível encontrar conteúdos vinculados ao ensino de Biologia e Ciências.

Apesar de ser uma crítica apontada por professores egressos de ambos os projetos curriculares analisados, foi possível identificar um avanço considerável na presença das temáticas relacionadas ao Ensino de Biologia a partir da reestruturação curricular de 2008. Entretanto, esses dados reforçam a necessidade de um contínuo crescimento no percentual de disciplinas vinculadas ao campo do Ensino no currículo da Licenciatura em Ciências Biológicas da UFPB, bem como o aperfeiçoamento das ementas das disciplinas didático-pedagógica em direção à promoção de uma maior contextualização entre as disciplinas da Educação e o Ensino de Biologia.

Pitolli (2014), ao investigar a concepção de licenciandos e ex-graduados sobre a restruturação curricular de uma Licenciatura em Ciências Biológicas de São Carlos (SP), identificou uma grande valorização da disciplina Pesquisa em Ensino por parte dos participantes do estudo, os quais afirmaram só conhecer qualquer pesquisa da área de Educação e Ensino por causa dessa disciplina. No trabalho de Camargo, Nardi e Rubo (2014, p.34), também foi identificada essa demanda por mais disciplinas voltadas para o ensino da ciência base da formação, como pode ser observado no relato:

[...] você não via iniciação na área de ensino de Física. Era totalmente voltada para a área de pesquisa em Física [...] e por aí afora... você não tinha iniciação científica na área de ensino de Física, esse é um ponto que também complica. [relato do prof.02]

A soma entre a pequena quantidade de disciplinas e os poucos professores universitários com algum tipo de experiência ou formação na área de Ensino de Biologia repercute na produção dessas demandas formativas por parte dos atuais professores. Para Camargo, Nardi e Rubo (2014), esse problema interfere, inclusive, no desenvolvimento dos trabalhos de conclusão de curso nas Licenciaturas das Ciências Naturais, visto que, muitas das vezes, os licenciados não conseguem encontrar orientadores para auxiliar o desenvolvimento de suas pesquisas. No trabalho de Pitolli (2014, p. 156), o mesmo problema referente à pouca quantidade de professores com formação acadêmica na área de ensino de Ciências e Biologia é levantado:

(...) um aspecto considerado como problemático em relação à pesquisa ser obrigatoriamente desenvolvida na área de educação é a questão do reduzido número de professores para desenvolver atividades de orientação na área. 
A pouca quantidade de professores universitários especializados na área de Educação e Ensino vem gerando uma série de influências negativas no desenvolvimento da formação docente. Os professores universitários formulam os currículos formais e reais da licenciatura e, sem terem formação acadêmica na área, tendem a não compreender de forma completa os reais desafios da formação de profissionais para o contexto escolar. Além disso, ao não realizarem pesquisas envolvendo a área pedagógica (vinculada à ciência base com a qual trabalham), não formam outros pesquisadores educacionais nem destacam a importância da utilização das pesquisas científicas para o constante avanço da prática pedagógica dos futuros professores; repercutindo negativamente na formação do pesquisador educacional e do futuro professor da educação básica e superior.

\section{Algumas teorias didático-pedagógicas da formação são pouco viáveis na escola}

Uma outra concepção recorrente, que aprofunda a crítica à ausência da dimensão do Ensino de Biologia no curso de Licenciatura em Ciências Biológicas da UFPB, foi a de que as atividades e teorias que aprenderam no curso eram pouco aplicáveis na escola. Professores egressos de ambos os currículos analisados identificaram um distanciamento entre o conhecimento (e as práticas) que foram ensinadas na formação inicial e o que necessitaram quando se tornaram professores de Biologia do ensino médio.

(...) os professores estão ali apenas para transmitir informações, mas eles não tão trazendo e dizendo: "Olha, vocês em sala de aula vão ter esse tipo de questionamento, a sala é assim.", ele não prepara você para uma sala de aula. (Prof. 04)

(...) a parte relacionada à licenciatura deixou muito a desejar, porque as disciplinas não alcançavam a prática de sala de aula, eram teóricas, eram enfadonhas, eram disciplinas que a gente não via a práxis, não tinha sentido a forma de abordar. (Prof. 09)

Algumas teorias pedagógicas e muitas das práticas que foram apresentadas durante as disciplinas da área pedagógica não tinham relação com o que os participantes do estudo encontraram quando se tornaram professores. Quando o prof. 09 relata que "eram disciplinas que a gente não via a práxis, não tinha sentido a forma de abordar a disciplina, ou o conteúdo se encaixar", ele ressalta a ausência de relação entre as teorias que aprendia nas disciplinas didático-pedagógicas e a prática de ensino na educação básica.

(...) porque é muito utópico o que se tem nos livros (...) a sala de aula é bem diferente, não dá pra aplicar nenhuma teoria que eu vi, não dá! Pelo menos não da forma que se coloca, dá pra adaptar. (Prof. 09)

(...) pra mim faltou muito essa parte mais prática. De preparação de plano de aula a gente teve muito por cima, foi algo muito superficial, você não vem preparado pra enfrentar o que a gente vê em sala de aula. (Prof. 01)

Tais relatos indicam que nas disciplinas didático-pedagógicas ocorre um fenômeno similar às disciplinas específicas, com a desarticulação entre saberes teóricos 
e práticos no currículo real do curso. Nessas disciplinas o conhecimento sobre Psicologia da Educação, Sociologia, História e Filosofia eram trabalhados sem apresentar conexões com a dimensão didática, com o campo do Ensino de Biologia, reduzindo o potencial de aprendizagem das aulas e o significado atribuído a esses conteúdos por parte dos licenciandos de Ciências Biológicas.

Essa dificuldade que o professor apresenta em desenvolver na escola o que aprendeu na licenciatura também foi um tema citado por participantes dos estudos de Oliveira (2004), Pandolpho (2006) e Souza e Fonseca (2014). No artigo de Souza e Fonseca (2014), os professores relataram querer desenvolver as teorias aprendidas na formação inicial, mas essas teorias pareciam inviáveis na realidade da escola básica: "quando formados, os professores chegam à sala de aula com dificuldades de transformar o ideal aprendido em algo realizável” (Souza, \& Fonseca, 2014, p. 6229).

No estudo de Oliveira (2004, p. 96) o mesmo pôde ser observado no relato de uma professora que afirmou: "O que a gente discute nas disciplinas de licenciatura, muitas vezes está um pouco distante daquilo que acontece na sala”. No trabalho de Pandolpho (2006, p. 108) a mesma temática foi observada:

As respostas mostram que sentiram falta de um acompanhamento mais profundo em relação à realidade escolar, situações-problema em sala de aula, necessidade de professores mais bem preparados para adequar sua metodologia ao uso efetivo em escolas de ensino médio, salientaram poucas aulas práticas no laboratório e que as que tiveram não eram aplicáveis às escolas que teriam que atuar. (Pandolpho, 2006, p. 108)

Para Leite (2004) e Oliveira (2004) essa concepção se origina de um entendimento equivocado sobre a relação entre teoria e prática, reforçado pela recorrência de projetos curriculares que separam componentes curriculares teóricos de componentes práticos. Produz-se, assim, uma compreensão que dissocia essas duas dimensões e promove uma concepção que as separa e supervaloriza as práticas em relação às teorias.

Entretanto, não pareceu existir um equívoco nessa compreensão por parte dos professores investigados em nosso estudo. O que identificamos foi que, para eles, a valorização da prática não foi fruto de uma compreensão conceitual simplificada e equivocada sobre a relação entre teoria e prática, mas sim de uma real demanda por mais relação entre as teorias que se aprende na formação inicial e os contextos escolares (sobretudo com o campo da Didática). O que eles entendem por "prática" pode então ser compreendido como "realidade escolar", o espaço em que os saberes se fundem e se materializam em ações didático-pedagógicas. No entendimento dos relatos presentes em nosso trabalho, quando o professor critica a ausência de "prática" na sua formação inicial ele não se refere, exclusivamente, às aulas práticas, ele fala da "prática" como a "realidade escolar".

\section{Conclusões e Implicações}

As concepções docentes sobre formação inicial, presentes nos relatos de experiência de professores de Biologia de ensino médio, apontaram a ocorrência de êxitos 
e críticas que transitaram do impacto dos programas extracurriculares até aspectos do currículo formal e real do curso de Licenciatura em Ciências Biológicas analisado.

No que se refere aos êxitos, pudemos identificar a importância atribuída ao papel formativo exercido pelos projetos extracurriculares voltados à pesquisa educacional e iniciação docente (em especial do PIBID), reforçando os apontamentos dos trabalhos de Feitosa e Gomes (2016) e Sousa et al. (2016). Percebemos que a valorização desses projetos se fundamenta no entendimento de que se constituem como programas de desenvolvimento integrado entre os saberes docentes, através da conexão entre conhecimentos didático-pedagógicos que acessaram no curso e a prática de ensino no contexto da escola básica, bem como de aprendizagens sobre a pesquisa qualitativa em Ensino e Educação. Os professores também destacaram seu papel no desenvolvimento de um sentimento de superação das inseguranças no que tange os desafios da profissão, fortalecendo seus processos de identificação profissional docente.

Essa concepção está de acordo com os apontamentos de Lüdke (2009), indicando que os professores atuantes também compreendem que a pesquisa e o ensino devem se complementar para o desenvolvimento da formação de professores e pesquisadores no Brasil. Acrescentamos, no entanto, o entendimento de que é fundamental que nas licenciaturas em Ciências Biológicas se estimule a criação e manutenção de programas especificamente direcionadosàsáreas de Educação e Ensino, pois nestes cursos a dimensão da pesquisa é, na maioria dos casos, exclusivamente vinculada às áreas específicas, o que pode levar essa conexão entre formação e pesquisa a fragilizar o projeto de identificação formativa e profissional dos licenciandos com a escola.

Nesse tema, destacamos que durante o processo de amostragem dessa pesquisa entramos em contato com 49 licenciados formados no currículo de 2008, e 31 deles nunca tinham trabalhado em escolas, sendo que todos os cinco professores que participaram da pesquisa participaram do PIBID. Dos outros cinco professores entrevistados (formados no currículo de 1987), apenas um não havia participado de programas de pesquisa educacional ou monitoria de disciplinas. Tais dados reforçam o entendimento da importância dos programas extracurriculares de pesquisa educacional e iniciação à docência para o processo de fortalecimento da identificação formativa e profissional com o campo da Educação. Todavia, trata-se de uma temática complexa que demanda a realização de futuras pesquisas que se aprofundem no assunto de forma específica.

Ressaltamos também que, por mais exitosos que sejam esses programas extracurriculares, eles se destinam a uma pequena parcela de licenciandos e, por isso, não podemos negligenciar a importância dos estágios curriculares para a democratização do acesso a um curso de formação docente de qualidade. É necessário incorporar os êxitos apresentados por esses programas à estrutura curricular das licenciaturas, modificando e ajustando os estágios supervisionados para atingir seus objetivos curriculares e formativos de conexão entres os saberes docentes e a articulação entre teoria e prática durante a formação inicial de professores.

Ainda na dimensão dosêxitos, o saber disciplinar e as aulas práticas demonstrativas 
foram destacados como aspectos bem desenvolvidos no decorrer da formação inicial. Apesar de este resultado apontá-los como aspectos positivos da licenciatura analisada, nosso estudo identificou que os professores entrevistados ressaltam a necessidade de que os docentes formadores das disciplinas específicas incorporem às suas aulas (teóricas e práticas) a dimensão dos saberes profissionais e curriculares, isto é, passem a ensinar os conteúdos específicos de forma integrada à dimensão didática do "como ensinar" esses conteúdos e relacionem o currículo escolar com os temas que devem ser trabalhados na universidade.

No contexto das críticas, os relatos indicaram de forma contundente que em várias disciplinas específicas os docentes formadores não ministravam aulas com o objetivo de formar um licenciando (futuro professor), mas com o objetivo de formar um bacharel (técnico-pesquisador nas áreas específicas da Biologia). Essa descaracterização da formação docente corrobora os relatos de professores de Física nas pesquisas de Camargo, Nardi e Rubo (2014) e Garcia e Pozo (2017). Nosso trabalho identificou a ocorrência do mesmo fenômeno em um curso de Licenciatura em Ciências Biológicas, indicando a amplitude e complexidade dessa questão.

Em relação aos componentes didático-pedagógicos, os professores entrevistados relataram a baixa quantidade de disciplinas diretamente voltadas à área de Ensino de Ciências e Biologia. Das seis disciplinas pedagógicas obrigatórias do currículo de 1987 em apenas uma existia a temática do Ensino de Ciências e Biologia na ementa, enquanto que em nove das 16 disciplinas pedagógicas do currículo de 2008 a temática era apresentada nas ementas. Mesmo mostrando um avanço formativo significativo, esses relatos nos fazem perceber como a influência das concepções formativas que culminaram no currículo " $3+1$ " ainda fazem parte do universo das licenciaturas, mantendo um espaço curricular similar aos componentes didático-pedagógicos. Identificar que os professores da escola básica se incomodam com essa realidade é um potente indicativo da pertinência da questão e da necessidade de luta pela conquista de mais espaço, com a contratação de mais professores formadores que trabalhem na área de Educação e Ensino de Ciências.

Em relação ao currículo real dos componentes didático-pedagógicos, os professores relataram que muitas das atividades e teorias que aprenderam eram inviáveis de serem postas em prática no contexto escolar. Tal crítica que aponta a existência de uma demanda por mais contextualização entre as teorias pedagógicas que são ensinadas na formação inicial e a dimensão didática do trabalho docente. Por mais importantes que sejam os componentes relativos à Sociologia, Psicologia, Política, Filosofia e História da Educação, os professores entrevistados indicaram que os professores formadores dessas áreas deveriam destinar parte de seu currículo à contextualização desses conteúdos com a prática de ensino de Biologia.

Ao comparar o texto do currículo formal de 1987 com o de 2008, é possível identificar avanços consideráveis com a ampliação na quantidade de componentes curriculares voltados ao campo do ensino de Ciências e Biologia, modificação dos objetivos do curso, diferenciação do perfil profissional almejado, separação da entrada 
dos graduandos nas modalidades bacharelado e licenciatura, entre outros. Considerar essas características no planejamento inicial da pesquisa nos levou a pressupor que encontraríamos grandes diferenças nas concepções de formação dos professores egressos de cada projeto curricular; porém, a maioria dos temas apresentou grande similaridade no corpo dos relatos analisados. Entendemos então que o desafio de repercutir as reestruturações do currículo formal para o real deva passar pela constituição de espaços de formação continuada que tenham como objetivo a promoção de um diálogo coletivo real, que leve todos os docentes dos cursos de licenciatura a se envolverem com a formação em sua totalidade, compreendendo as mudanças nos objetivos formativos presentes no projeto pedagógico curricular do curso em que trabalham.

Por fim, destacamos as contribuições do presente estudo para área de formação docente em Ciências Biológicas, considerando que os resultados encontrados nos aproximam da compreensão sobre a maneira como os profissionais que vivenciam o cotidiano da educação básica refletem sobre as experiências que vivenciaram durante o curso de licenciatura. Tais resultados podem contribuir para que as futuras restruturações curriculares consigam acessar as repercussões profissionais das formações passadas, apresentando, portanto, a intenção de promover um diálogo entre quem planeja e executa, e quem vivencia e é formado nas Licenciaturas em Ciências Biológicas brasileiras.

\section{Agradecimentos}

Agradecemos a todas as professoras e professores que participaram da pesquisa e ao Programa de Pós-Graduação em Educação da UFPB. Ressaltamos, também, que o presente trabalho foi realizado com apoio da Coordenação de Aperfeiçoamento de Pessoal de Nível Superior - Brasil (CAPES) - Código de Financiamento 001.

\section{Referências}

Ayres, A. C. M. (2005). As tensões entre a licenciatura e o bacharelado: a formação de professores de Biologia como território contestado. In M.,Marandino, S. E. Selles, M. S., Ferreira, \& A. C., Amorim (Orgs.), Ensino de Biologia: conhecimentos e valores em disputa (pp. 182-197). Niterói: EDUFF.

MEC (2001). Diretrizes Curriculares Nacionais para a Formação de Professores da Educação Básica, em nível superior, curso de licenciatura, de graduação plena. Parecer CNE/CP no 009/2001, de 8 de Maio.

Cacete, N. H. (2014). Breve história do ensino superior brasileiro e da formação de professores para a escola secundária. Educação e Pesquisa, 40(4), 1061-1076. http:// dx.doi.org/10.1590/S1517-97022014005000011

Camargo, S., Nardi, R., \& Rubo, E. A. A. (2014). Demandas de Professores de Física em Exercício no Ensino Médio: Subsídios para um Processo de Reestruturação de um Curso de Licenciatura. Revista Brasileira de Pesquisa em Educação em Ciências, 14(3), 13-40. 
Carvalho, A. M. P, \& Gil-Pérez, D. (2011). Formação de professores de Ciências: tendências e inovações. 10. ed. São Paulo: Cortez.

Colaizzi, P. F. (1978). Psychological Research as the Phenomenologist Views It, In R. S. Valle, \& M. King. Existential Phenomenological Alternatives for Psychology. (pp. 48-71). Nova York, NY: Oxford University Press.

Creswell, J. W. (2014). Investigação qualitativa e projeto de pesquisa: escolhendo entre cinco abordagens. 3. ed. Porto Alegre: Penso.

Diniz-Pereira, J. E. (2000). Formação de professores: pesquisa, representações e poder. Belo Horizonte: Autêntica.

Feitosa, R. A., \& Gomes, A. D. C. (2016). Contribuições do Programa Institucional de Bolsas de Iniciação à Docência (PIBID) para a formação docente na área de matemática. Revista Eletrônica Debates em Educação Científica e Tecnológica, 6(2), 116-130.

Feitosa, R. A., \& Leite, R. C. M. (2011). O trabalho e o saber docente: construindo a mandala do professor artista-reflexivo. Rio de Janeiro: Câmara Brasileira de Jovens Escritores.

Garcia, I. K., \& Pozo, J. I. (2017). Concepções de professores de Física sobre ensinoaprendizagem e seu processo de formação: um estudo de caso. Investigação em Ensino de Ciências, 22(2), 96-119. http://dx.doi.org/10.22600/1518-8795.ienci2017v22n2p96.

Krasilchik, M. (2004). Prática de ensino de biologia. 4. ed. São Paulo: Edusp.

Leite, M. A. (2004). Formação docente: Ciências e Biologia estudo de caso. Bauru: EDUSC.

Libâneo, J. C. (2001). Organização e gestão da escola: Teoria e Prática. Goiânia: Alternativa.

Lüdke, M. (2009). Universidade, escola de educação básica e o problema do estágio na formação de professores. Revista Brasileira de Pesquisa Sobre Formação Docente, 1(1), 95-108.

Matos, D. A. S., \& Jardilino, J. R. L. (2016). Os conceitos de concepção, percepção, representação e crença no campo educacional: similaridades, diferenças e implicações para a pesquisa. Revista Educação \& Formação, 1(3), 20-31. http://dx.doi.org/10.25053/ edufor.v1i3.1893

Moreira, D. A. (2004). O método fenomenológico na pesquisa. 1. ed. São Paulo: Pioneira Thomson Learning.

Oliveira, M. P. D. B. (2004). Construindo a trajetória docente: os percursos formativos de professores de ciências. (Dissertação de Mestrado em Educação). Centro de Educação e Ciências Humanas de São Carlos, São Carlos. 
Pandolpho, M. H. S. (2006). O Ensino de Biologia em questão: Os vazios e as referências da graduação na prática docente sob o olhar de egressos. (Dissertação de Mestrado em Educação). Centro de Ciências Sociais Aplicada de Campinas, Campinas, São Paulo.

Pimenta, S. G. (2012). Saberes pedagógicos e atividade docente. ed. 8. São Paulo: Cortez.

Pitolli, A. M. S. (2014). A formação inicial de professores de Ciências e Biologia: uma análise a partir da visão de licenciandos de uma universidade pública. (Dissertação de Mestrado em Educação). Centro de Educação e Ciências Humanas de São Carlos, São Paulo.

Sampieri, R. H., Collado, C. F., \& Lúcio, M. P. B. (2013). Metodologia de Pesquisa. ed. 5. São Paulo: McGraw Hill.

Sousa, E. T., Feitosa, R. A., Gomes, A. D. C., Ferreira, Y. B., \& Sousa, R. S. (2016). Formação inicial de professores: um estudo do PIBID-BIOLOGIA em Crateús-CE. Revista da SBEnBio, 9(1), 3215-3223.

Sousa, R. F., Moura, F. M. T., \& Sá-Carneiro, C. C. B. (2013). O Papel da didática das ciências na formação do professor. In R. I. C., Gullich (Org.), Didática das Ciências (pp. 51-63). Curitiba: Prisma.

Souza, P. A. R., \& Fonseca, L. C. F. (2014). Licenciatura em Ciências Biológicas: memórias de uma formação inicial. Revista da SBEnBio, 7(1), 6222-6233.

Tardif, M. (2014). Saberes docentes e formação profissional. 17. ed. Rio de Janeiro: Vozes. 
Ravi Cajú Duré

${ }^{(1)}$ http://orcid.org/0000-0003-1040-5071

Universidade Federal da Paraíba Programa de Pós-Graduação em Educação João Pessoa, Paraíba, Brasil ravicdure@gmail.com

Francisco José Pegado Abílio

(다tp://orcid.org/0000-0002-7217-4849

Universidade Federal da Paraíba Centro de Educação, Departamento de Metodologia da Educação João Pessoa, Paraíba, Brasil chicopegado@yahoo.com.br

Submetido em 10 de janeiro de 2019 Aceito em 14 de agosto de 2019 Publicado em 09 de setembro de 2019 